\title{
A decreasing trend in toxoplasma gondii seroprevalence among pregnant women in Romania - results of a large scale study
}

\author{
SORIN MOTOI $^{1 *}$, DAN BOGDAN NAVOLAN ${ }^{2 *}$, DANIEL MALITA $^{1}$, IOANA CIOHAT $^{3}$, \\ DRAGOS NEMESCU ${ }^{4}$, CARMEN MANCIUC $^{5}$, FLORIN GORUN $^{2}$, TATJANA VILIBIC-CAVLEK ${ }^{6}$, \\ DANIEL BODA $^{7,8}$, MARIUS CRAINA ${ }^{2}$ and AMADEUS DOBRESCU ${ }^{9}$ \\ Departments of ${ }^{1}$ Medical Imaging and Radiology, and ${ }^{2}$ Obstetrics and Gynecology, \\ 'Victor Babes' University of Medicine and Pharmacy, 300041 Timisoara; ${ }^{3}$ Antenatal Laboratory, \\ Emergency Clinical City Hospital, 300202 Timisoara; Departments of ${ }^{4}$ Obstetrics and Gynecology, \\ and ${ }^{5}$ Infectious Diseases, 'Grigore T. Popa' University of Medicine and Pharmacy, 700115 Iasi, Romania; \\ ${ }^{6}$ Department of Virology, Croatian National Institute of Public Health and School of Medicine, University of Zagreb, \\ 10000 Zagreb, Croatia; ${ }^{7}$ Dermatology Research Laboratory, 'Carol Davila' University of Medicine and Pharmacy, \\ 050474 Bucharest; ${ }^{8}$ Department of Dermatology, 'Prof. N. Paulescu' National Institute of Diabetes, \\ Nutrition and Metabolic Diseases, 79811 Bucharest; 'Department of Surgery, 'Victor Babes' \\ University of Medicine and Pharmacy, 300041 Timisoara, Romania
}

Received June 10, 2020; Accepted July 10, 2020

DOI: $10.3892 / \mathrm{etm} .2020 .9012$

\begin{abstract}
Toxoplasmosis is a zoonotic infection caused by the obligate intracellular apicomplexan parasite Toxoplasma gondii (T. gondii). T. gondii infection is a cause of congenital infection worldwide. Primary infection or the reactivation of latent infection during pregnancy may lead to fetal infection and to congenital toxoplasmosis syndrome. Seropositive pregnant women are generally protected from maternal-fetal transmission of $T$. gondii, although exceptions exist. The aim of our study was to analyze the dynamics of $T$. gondii seroprevalence during a 10 -year period and to correlate it with age and demographic features of pregnant women. We tested 6,889 pregnant women in Timisoara, Romania, for IgG-anti- $T$. gondii antibodies, in two successive periods: i) 2008-2010 (group 1: 1,457 participants); and ii) 2015-2018
\end{abstract}

Correspondence to: Dr Carmen Manciuc, Department of Infectious Diseases, 'Grigore T. Popa' University of Medicine and Pharmacy, 16 Universitatii Street, 700115 Iasi, Romania

E-mail:dmanciuc@yahoo.com

Dr Dragos Nemescu, Department of Obstetrics and Gynecology, 'Grigore T. Popa' University of Medicine and Pharmacy, 16 Universitatii Street, 700115 Iasi, Romania

E-mail:dnemescu@yahoo.com

${ }^{*}$ Contributed equally

Abbreviation: T. gondii; Toxoplasma gondii

Key words: Toxoplasma gondii, seroprevalence, demography, pregnant women, congenital toxoplasmosis syndrome (group 2: 5,432 participants). For each participant, data on age and area of residence were collected. Our results showed that in the Western Region of Romania T. gondii seroprevalence in pregnant women declined from 43.79 to $38.81 \%$ in the last ten years. This trend was observed in both urban (40.53 vs. $34.85 \%)$ and rural areas (52.22 vs. $46.22 \%$ ). A higher seroprevalence rate was found in rural than in urban areas. In addition, we found an increasing tendency of seroprevalence related to the age of pregnant women.

\section{Introduction}

Toxoplasmosis is a zoonotic infection caused by the obligate intracellular apicomplexan parasite Toxoplasma gondii (T. gondii) $(1,2) . T$. gondii can infect both birds and mammalians (3). However, the only hosts where the parasite's sexual reproduction takes places are the members of the Felidae family: Both domestic and wild cats (4).

Scientific reports showed that around one third of global population is infected with $T$. gondii (4). The contamination could occur by ingestion of sporulated oocysts present in contaminated soil, water or food (5). Ingestion of raw or undercooked meat from infected animals is the primary source of infection (5). Vertical transmission from infected mother to fetus is also possible (6), as well as transmission via blood products and graft tissue (7). A large European study found that traveling outside Europe and the United States of America or Canada is also considered a risk factor predictive of acute infection in pregnant women besides the ingestion of undercooked meat (lamb, beef, game), contaminated water or contact with contaminated soil (8).

T. gondii is a parasite with specific strategies to avoid the host's immune defenses and to establish a life-long infection that may influence in various modes the infected hosts (9). In 
immunocompetent persons infections are merely asymptomatic and self-limiting. In immunocompromised individuals and in the developing fetus, however, T. gondii may cause life-threatening infections (10). Congenital toxoplasmosis is caused by transplacental infection of the fetus. This could determine a spontaneous abortion, fetal demisse, intrauterine growth restriction, hydrocephalus, encephalitis, neurological, ocular or auditive diseases, inflammation or cardiovascular diseases $(6,11)$. Also, infection in pregnancy could be associated with preterm birth (12). The risk of vertical transmission is correlated with the gestational age at the time of infection. It is approximately $15 \%$ at $13,44 \%$ at 26 , and $71 \%$ at 36 weeks of pregnancy (13). Even if the risk of fetal infection is directly correlated with gestational age, the severity of fetal damage inversely correlates with gestational age, at the time the infection occurs (14).

The global incidence of congenital toxoplasmosis is approximately 190,000 cases each year with a rate of 1.5 cases $/ 1,000$ births. The incidence varies in different regions from 0.5-1.6/1,000 births in Europe, 0.4-3.4/1,000 births in America to 2.0-2.4/1,000 births in Africa $(15,16)$.

The global prevalence of toxoplasmosis is estimated between $25-30 \%(4,15)$. Within low prevalence areas (between 10-30\%) are: North America, North of Europe, South-East Asia and Sahelian Africa (16). Areas with a moderate seroprevalence (30-50\%) are Central and South of Europe (16). High seroprevalence areas are Latin America and Tropical Africa $(15,16)$.

Childbearing and pregnant women from different geographical zones showed different seroprevalence between $9 \%$ in the United Kingdom (17) and $48.7 \%$ in Bruxelles, Belgium (18). In 2015 in Romania, a study by Olariu et al (19) showed a seroprevalence of $57.6 \%$ in women at childbearing age (20).

The aim of our study was to analyse the dynamics of T. gondii seroprevalence during a 10-year period and to correlate it with age and demographic features of pregnant women.

\section{Patients and methods}

Study design, settings and patients. A cross-sectional study involving 6,889 adult pregnant women was performed in Timisoara, Romania in two successive periods: i) 2008-2010 (group 1: 1,457 patients at City Universitary Emergency Hospital, Timisoara, Romania); and ii) 2015-2018 (group 2: 5,432 patients at Bioclinica Laboratory srl, Timisoara, Romania). Patients were enrolled according to a consecutive-case population base. We collected data for each patient, namely age and area of residence.

Ethical issues. Approval from the Institutional Board of the 'Victor Babeş' University of Medicine and Pharmacy (Timisoara, Romania; approval no. 848/06.04.2011) was obtained to perform this study. The present study meets the ethical guidelines, including adherence to the legal requirements of the study country. Informed consent was obtained from each patient.

Serological testing. The IgG- anti-T. gondii antibodies titer was determined by the immune-chemiluminescence method using
Table I. Demographic characteristics of participants.

\begin{tabular}{lcc}
\hline & $\begin{array}{c}\text { Group 1 } \\
(2008-2010) \\
\mathrm{n}=1,457\end{array}$ & $\begin{array}{c}\text { Group 2 } \\
(2015-2018) \\
\mathrm{n}=5,432\end{array}$ \\
\hline Area of residence [n (\%)] & & \\
Urban & $1,051(71.15)$ & $3,541(65.19)$ \\
Rural & $406(27.87)$ & $1,891(34.11)$ \\
Age (years) & $28(6)^{\mathrm{a}}$ & $29(7)^{\mathrm{a}}$ \\
\hline
\end{tabular}

${ }^{\mathrm{a}} \mathrm{P}<0.001$.

an Immulite One Machine (Diagnostic Products Corporation) and commercial tests (Siemens Healthcare Diagnostics Products) for group 1 patients (2008-2010) and by chemiluminescent microparticle immunoassay (CMIA) method using an Architect i1000SR engine (Abbott) and commercial tests (Abbott) for group 2 patients (2015-2018). According to cut-off values we stratified patients into two categories: Those with positive test values of IgG antibodies; and those with negative or inconclusive $\mathrm{IgG}$ test values.

Statistical analysis. Data were stored in the Astraia database (Astraia Software $\mathrm{GmbH}$ ) and Microsoft Office Excel (Microsoft Corporation). Instat GraphPad Prism Software (GraphPad Software, Inc.) was used for statistical analysis. The results are presented as medians and (interquartile ranges). Mann-Whitney-U, respectively Fisher's exact tests (proportions) were used to assess the differences between groups. Cochran-Armitage test (Chi-square test for trend) was used to evaluate the association between seroprevalence rate and age of pregnant women. $\mathrm{P}<0.05$ was considered to indicate a statistically significant difference.

\section{Results}

Demographic characteristics of pregnant women. Among women in group $1,71.15 \%(1,051 / 1,457)$ declared to be from urban and $27.85 \%(406 / 1,457)$ from a rural area, while of women in group $2,65.19 \%(3,541 / 5,432)$ were from urban and $34.11 \%(1,891 / 5,432)$ from rural areas (Table I).

Pregnant women from group 1 (2008-2010) were younger than those from the group $2(2015-2018): 28$ years $(n=6)$ vs. 29 years $(n=7),(P<0.001$; Table I).

Seroprevalence results. Of the 1,457 women included in group 1, $638(43.79 \%)$ were tested positive, $812(55.73 \%)$ negative and $7(0.48 \%)$ inconclusive, while of the 5,432 women included in the group 2, 2,108 (38.81\%) were tested positive, $3,210(59.09 \%)$ negative and $114(2.10 \%)$ inconclusive for the presence of IgG-anti-T. gondii antibodies.

Women from urban areas showed lower seroprevalence rates compared with those from rural areas: Group 1 (2008-2010) 40.53 vs. $52.22 \%(\mathrm{P}<0.001)$ or group $2(2015-2018) 34.85$ vs. $46.22 \%(\mathrm{P}<0.001$; Table II).

A decreasing trend was found of IgG-anti-T. gondii seroprevalence in pregnant women. In the first tested period 
Table II. Seroprevalence to Toxoplasma gondi according to the area of residence and age of pregnant women.

\begin{tabular}{lccc}
\hline Variables & Group 1: 2008-2010, $\mathrm{n}=1,457$ & Group 2: 2015-2018, $\mathrm{n}=5,432$ & P-value \\
\hline Overall seroprevalence & $638(43.79 \%)$ & $2,108(38.81 \%)$ & $<0.001$ \\
Area of residence & & & \\
Urban & $426 / 1,051(40.53 \%)$ & $1,234 / 3,541(34.85 \%)$ & $<0.001$ \\
Rural & $212 / 406(52.22 \%)$ & $874 / 1,891(46.22 \%)$ & $<0.05$ \\
P-value & $<0.001$ & $<0.001$ & \\
Age interval, years & & $606 / 1,595(37.99 \%)$ & \\
$18-26$ & $216 / 527(40.99 \%)$ & $1,172 / 3,078(38.07 \%)$ & \\
$27-35$ & $346 / 836(44.98 \%)$ & $330 / 759(43.47 \%)$ & \\
$\geq 36$ & $46 / 94(48.94 \%)$ & 0.035 & \\
P-value & 0.074 & & \\
\hline
\end{tabular}

the seroprevalence was found to be $43.79 \%$ compared with $38.81 \%$ in the second tested period $(\mathrm{P}<0.001)$. This trend was observed in pregnant women from both urban $[40.53$ vs. 34.85\% $(\mathrm{P}<0.001)]$ and rural $[52.22$ vs. $46.22 \%(\mathrm{P}=0.02)]$ areas (Table II).

We found an increasing tendency of seroprevalence with the age of pregnant women, thus women older than 36 years had a higher seroprevalence rate than women aged 27-35 years or younger than 26 years. The difference was observed in both groups, however a significant value was found only in the second group $(\mathrm{P}=0.035)$, while in the first group the significance was borderline $(\mathrm{P}=0.074$; Table II).

\section{Discussion}

We found that 62.3 and $56.26 \%$ of pregnant women from group 1, and respectively from group 2 were susceptible to a primary $T$. gondii infection in our region. In low seroprevalence regions the risk of contacting an infection is low but if a contamination occurs, the risk of primary infection is high. On the contrary, in high prevalence regions the risk of a pregnant women to contract a primary infection is low because the majority of pregnant women are seropositive. However, in the context of iatrogenic immunosuppression or of a disease that causes immunosuppresion, a reinfection may occur. Also, contamination with other $T$. gondii strains may lead to a reinfection in an immunocompetent organism (21).

The global $T$. gondii seroprevalence in the general population is approximately $25-30 \%(4,15)$. Studies from the United States of America (USA) showed that the prevalence in the USA has continued to decline from 14 to $23 \%$ (1988-1994), to 9\% (1999-2004) and 6\% (2009-2010) (22,23). Research from other regions showed a general seroprevalence approximately 44\% in France (24), between 51 and $72 \%$ in Latin America and between 5 and 35\% in Asia, China and Korea (25).

Data on childbearing age women showed a seroprevalence of 9\% in Great Britain (17), between 16 and 29\% in Spain (26), approximately $24 \%$ in North of Portugal (27), $29.1 \%$ in Croatia (28), 44\% in France (29) and $19 \%$ in Italy (30). Other studies showed a seroprevalence of $9.1 \%$ in 2009 in the USA (22). Thus, showed that pregnant women from our region fit in a moderate level of seroprevalence. However, in Europe only women from France showed a higher seroprevalence (29).

A study conducted by Olariu et al in 2008 showed a seroprevalence of $57.6 \%$ in women of childbearing age (19). Our results showed a decresing trend in the seroprevalence among pregnant women from our region from $43.72 \%$ (2008-2010) to $38.70 \%$ (2016-2018). Likewise, a decrease in the seroprevalence rate was found in the USA from $14.9 \%$ (1988-1994), to $11.1 \%$ (2004) and to $9.1 \%$ (2009-2010) (22). Studies by Villena et al reported in France a decrease in seroprevalence in pregnant women from 66\% (1980), to 54\% (1995) and 44\% (2003) (29). Similarly, researchers from Netherlands showed a decline in seroprevalence in pregnant women from 32.5\% (1995-1996) to $18.5 \%$ (2006-2007) (31). Data on seroprevalence from many other European countries showed a similar decreasing trend: Austria [from $48 \%$ (1970) to $31-35 \%$ at present] $(32,33)$, Italy [from $31 \%$ (2001) to $21 \%$ in (2005)] (15), Portugal [from $31.4 \%$ (2005) to $24.4 \%$ (2010)] (30), and Poland [from $41.8 \%$ (2004) to $37.8 \%$ (2012)] (34).

The decreasing course of seroprevalence was found in both women from rural (52.22 vs. $46.22 \%$ ) and urban areas $(40.53 \%$ vs. $34.85 \%$ ) and could be explained by an improvement of socioeconomic and hygiene condition in the past ten years.

Our study showed a higher $T$. gondii seroprevalence in pregnant women from rural compared with women from urban areas, in both groups: Group 1 (52.22 vs. 40.53\%) and group 2 (40.53 vs. 34.85\%). Such results are in line with a previous study by Olariu et al which established the same trends in women (76 vs. 55.3\%) (35) and in children (18.4 vs. $14.7 \%$ ) (36). Other countries showed also higher seroprevalence rates in people from rural compared with urban areas: Mexico 32 vs. $12 \%$ (37) or Argentina 36.4 vs. 26.8\% (38). This variation can be attributed to the lower socio-economic level in some rural areas compared with urban ones, as well as to the less easy access to some services, such as running water, in some of these areas. An epidemiological profile with an increased risk of seropositivity for $T$. gondii is represented by a lower educational status, a lower economic level, without an occupation outside the household, and people living in a household without running water resources. These risk factors are more common in rural and suburban areas, areas with poor 
socioeconomic conditions with more frequent contact with animals, and eating habits, which may explain the association with a higher seroprevalence $(39,40)$.

Our results confirm the studies of Vilibic-Cavlek in Croatia and Olariu in Romania, showing an age-related increase in seroprevalence $(28,35)$.

It should be noted that a limitation of the study could be the fact that the two institutions in which the patients were tested might be slightly different in accessibility. The clinical hospital is a public institution while the Bioclinica laboratory is a private institution. This might, theoretically, indicate a different social structure of the patients tested in the two institutions/groups: 2008-2010 and 2015-2018. However, we consider that this aspect could be negligible because in both institutions the tests were done at a similar cost, so that the effect of patient selection on economic and social criteria is probably minimal. Future studies should, therefore, confirm this decreasing trend in seroprevalence for $T$. gondii. We include screening for TORCH agents along with first and second trimester screening in antenatal care program (41-43).

In conclusion, in the Western Region of Romania T. gondii seroprevalence in pregnant women has declined from 43.79 to $38.81 \%$ in the past ten years. This trend was found in both urban (40.53 vs. $34.85 \%$ ) and rural areas (52.22 vs. $46.22 \%$ ). A higher seroprevalence rate was found in rural than in urban areas. In addition, we found an increasing tendency of seroprevalence related to the age of pregnant women. Future studies should, therefore, confirm this decreasing trend in seroprevalence for T. gondii.

\section{Acknowledgements}

Not applicable.

\section{Funding}

No funding was received.

\section{Availability of data and materials}

The datasets used and/or analyzed during the present study are available from the first author on reasonable request.

\section{Authors' contributions}

DBN, SM, DN, CM, DB and TVC were involved in the conception of the study and the interpretation of the data. DM, DBN, SM, IC, FG, MC and AD contributed to the acquisition of the data and performed statistical analysis. IC performed serological testing. DBN, DN, IC, FG and TVC wrote the manuscript. SM, DM, MC, DB and AD revised the manuscript for important intellectual content. All authors read and approved the final version of the manuscript.

\section{Ethics approval and consent to participate}

The study meets the ethical guidelines, including adherence to the legal requirements of the study country. The study was approved by the Institutional Board of the 'Victor Babes' University of Medicine and Pharmacy (Timisoara, Romania; approval no. 848/06.04.2011). Informed consent was obtained from each patient.

\section{Patient consent for publication}

Not applicable

\section{Competing interests}

The authors declare that they have no competing interests.

\section{References}

1. Iemmi T, Vismarra A, Mangia C, Zanin R, Genchi M, Lanfranchi P, Kramer LH, Formenti N and Ferrari N: Toxoplasma gondii in the Eurasian kestrel (Falco tinnunculus) in northern Italy. Parasit Vectors 13: 262, 2020.

2. Ybañez RHD, Ybañez AP and Nishikawa Y: Review on the current trends of toxoplasmosis serodiagnosis in humans. Front Cell Infect Microbiol 10: 204, 2020.

3. Duong HD, Appiah-Kwarteng C, Takashima Y, Aye KM, Nagayasu E and Yoshida A: A novel luciferase-linked antibody capture assay (LACA) for the diagnosis of Toxoplasma gondii infection in chickens. Parasitol Int 77: 102125, 2020.

4. English ED and Striepen B: The cat is out of the bag: How parasites know their hosts. PLoS Biol 17: e3000446, 2019

5. Foroutan M, Fakhri Y, Riahi SM, Ebrahimpour S, Namroodi S, Taghipour A, Spotin A, Gamble HR and Rostami A: The global seroprevalence of Toxoplasma gondii in pigs: A systematic review and meta-analysis. Vet Parasitol 269: 42-52, 2019.

6. Olariu TR, Press C, Talucod J, Olson K and Montoya JG: Congenital toxoplasmosis in the United States: Clinical and serologic findings in infants born to mothers treated during pregnancy. Parasite 26: 13, 2019.

7. Sanchez-Petitto G, Holtzman NG, Bukhari A, Brown M, Morales MK, Koka M, Yared JA, Dahiya S, Rapoport AP and Hardy NM: Toxoplasma-induced hemophagocytic lymphohistiocytosis after haploidentical allogeneic stem cell transplantation. Transpl Infect Dis 22: e13242, 2020.

8. Cook AJ, Gilbert RE, Buffolano W, Zufferey J, Petersen E, Jenum PA, Foulon W, Semprini AE and Dunn DT: Sources of Toxoplasma infection in pregnant women: European multicentre case-control study. European research network on congenital toxoplasmosis. BMJ 321: 142-147, 2000.

9. Lima TS and Lodoen MB: Mechanisms of human innate immune evasion by Toxoplasma gondii. Front Cell Infect Microbiol 9: 103,2019

10. Montoya JG and Liesenfeld O: Toxoplasmosis. Lancet 363: 1965-1976, 2004.

11. Khan $\mathrm{K}$ and Khan W: Congenital toxoplasmosis: An overview of the neurological and ocular manifestations. Parasitol Int 67: 715-721, 2018.

12. Freeman K, Oakley L, Pollak A, Buffolano W, Petersen E, Semprini AE, Salt A and Gilbert R; European Multicentre Study on Congenital Toxoplasmosis: Association between congenital toxoplasmosis and preterm birth, low birthweight and small for gestational age birth. BJOG 112: 31-37, 2005.

13. Thiébaut R, Leproust S, Chêne G and Gilbert R; SYROCOT (Systematic Review on Congenital Toxoplasmosis) study group: Effectiveness of prenatal treatment for congenital toxoplasmosis: A meta-analysis of individual patients' data. Lancet 369: 115-122, 2007.

14. Kravetz J: Congenital toxoplasmosis. BMJ Clin Evid 2013: 0906, 2013.

15. Robert-Gangneux F and Dardé ML: Epidemiology of and diagnostic strategies for toxoplasmosis. Clin Microbiol Rev 25: 264-296, 2012.

16. Torgerson PR and Mastroiacovo P: The global burden of congenital toxoplasmosis: A systematic review. Bull World Health Organ 91: 501-508, 2013.

17. Nash JQ, Chissel S, Jones J, Warburton F and Verlander NQ: Risk factors for toxoplasmosis in pregnant women in Kent, United Kingdom. Epidemiol Infect 133: 475-483, 2005.

18. Breugelmans M, Naessens A and Foulon W: Prevention of toxoplasmosis during pregnancy - an epidemiologic survey over 22 consecutive years. J Perinat Med 32: 211-214, 2004. 
19. Olariu TR, Cretu O, Darabus GH, Marincu I, Jurovits O Erdelean V, Tirnea L, Neghina R, Iacobiciu I, Petrescu C and Koreck A: Screening for Toxoplasma gondii antibodies among women of childbearing age, in Timis County, Romania. In Proceedings of the 13th International Congress of Infectious Diseases, Kuala Lumpur, Abstract 489, 2008.

20. Pappas G, Roussos N and Falagas ME: Toxoplasmosis snapshots: Global status of Toxoplasma gondii seroprevalence and implications for pregnancy and congenital toxoplasmosis. Int J Parasitol 39: 1385-1394, 2009.

21. Pomares C, Devillard S, Holmes TH, Olariu TR, Press CJ, Ramirez R, Talucod J, Estran R, Su C, Dubey JP, et al: Genetic characterization of Toxoplasma gondii DNA samples isolated from humans living in North America: An unexpected high prevalence of atypical genotypes. J Infect Dis 218: 1783-1791, 2018.

22. Jones JL, Kruszon-Moran D, Rivera HN, Price C and Wilkins PP: Toxoplasma gondii seroprevalence in the United States 2009-2010 and comparison with the past two decades. Am J Trop Med Hyg 90: 1135-1139, 2014.

23. Centers for Disease Control and Prevention (CDC): Parasites-Toxoplasmosis: https://www.cdc.gov/mmwrpreview/mmwrhtml/ rr4902a5.htm. Accessed May 25, 2020.

24. Berger F, Goulet V, Le Strat Y and Desenclos JC: Toxoplasmosis among pregnant women in France: Risk factors and change of prevalence between 1995 and 2003. Rev Epidemiol Sante Publique 57: 241-248, 2009.

25. Rorman E, Zamir CS, Rilkis I and Ben-David H: Congenital toxoplasmosis - prenatal aspects of Toxoplasma gondii infection. Reprod Toxicol 21: 458-472, 2006.

26. Ramos JM, Milla A, Rodríguez JC, Padilla S, Masiá M and Gutiérrez F: Seroprevalence of Toxoplasma gondii infection among immigrant and native pregnant women in Eastern Spain. Parasitol Res 109: 1447-1452, 2011.

27. Lopes AP, Dubey JP, Moutinho O, Gargaté MJ, Vilares A, Rodrigues M and Cardoso L: Seroepidemiology of Toxoplasma gondii infection in women from the North of Portugal in their childbearing years. Epidemiol Infect 140: 872-877, 2012.

28. Vilibic-Cavlek T, Ljubin-Sternak S, Ban M, Kolaric B, Sviben M and Mlinaric-Galinovic G: Seroprevalence of TORCH infections in women of childbearing age in Croatia. J Matern Fetal Neonatal Med 24: 280-283, 2011.

29. Villena I, Ancelle T, Delmas C, Garcia P, Brezin AP, Thulliez P, Wallon M, King L and Goulet V; Toxosurv network and National Reference Centre for Toxoplasmosis: Congenital toxoplasmosis in France in 2007: First results from a national surveillance system. Euro Surveill 15: 19600, 2010.

30. Pinto B, Castagna B, Mattei R, Bruzzi R, Chiumiento L, Cristofani R, Buffolano W and Bruschi F: Seroprevalence for toxoplasmosis in individuals living in north west Tuscany: Access to toxo-test in central Italy. Eur J Clin Microbiol Infect Dis 31: 1151-1156, 2012.

31. Hofhuis A, van Pelt W, van Duynhoven YTHP, Nijhuis CDM, Mollema L, van der Klis FRM, Havelaar AH and Kortbeek LM: Decreased prevalence and age-specific risk factors for Toxoplasma gondii $\mathrm{IgG}$ antibodies in the Netherlands between 1995/1996 and 2006/2007. Epidemiol Infect 139: 530-538, 2011.
32. Edelhofer R and Prossinger H: Infection with Toxoplasma gondii during pregnancy: Seroepidemiological studies in Austria. Zoonoses Public Health 57: 18-26, 2010.

33. Sagel U, Krämer A and Mikolajczyk RT: Incidence of maternal Toxoplasma infections in pregnancy in Upper Austria, 2000-2007. BMC Infect Dis 11: 348, 2011.

34. Nowakowska D, Wujcicka W, Sobala W, Śpiewak E, Gaj Z and Wilczyński J: Age-associated prevalence of Toxoplasma gondii in 8281 pregnant women in Poland between 2004 and 2012. Epidemiol Infect 142: 656-661, 2014.

35. Olariu TR, Petrescu C, Darabus G, Lighezan R and Mazilu O: Seroprevalence of Toxoplasma gondii in Western Romania. Infect Dis (Lond) 47: 580-583, 2015.

36. Căpraru ID, Lupu MA, Horhat F and Olariu TR: Toxoplasmosis seroprevalence in Romanian children. Vector Borne Zoonotic Dis 19: 867-869, 2019.

37. Alvarado-Esquivel C, Campillo-Ruiz F and Liesenfeld O: Seroepidemiology of infection with Toxoplasma gondii in migrant agricultural workers living in poverty in Durango, Mexico. Parasit Vectors 6: 113, 2013.

38. Rivera EM, Lavayén SN, Sánchez P, Martins CMA, Gomez E, Rodriguez JP, Arias ME, Silva AP and Angel SO: Toxoplasma gondii seropositivity associated to peri-urban living places in pregnant women in a rural area of Buenos Aires province, Argentina. Parasite Epidemiol Control 7: e00121, 2019.

39. Belluco S, Mancin M, Conficoni D, Simonato G, Pietrobelli M and Ricci A: Investigating the determinants of Toxoplasma gondii prevalence in meat: A systematic review and meta-regression. PLoS One 11: e0153856, 2016.

40. Mareze M, Benitez ADN, Brandão APD, Pinto-Ferreira F, Miura AC, Martins FDC, Caldart ET, Biondo AW, Freire RL, Mitsuka-Breganó R and Navarro IT: Socioeconomic vulnerability associated to Toxoplasma gondii exposure in southern Brazil. PLoS One 14: e0212375, 2019.

41. Navolan D, Ionescu CA, Carabineanu A, Birsasteanu F, Cretu O, Szasz F, Vladareanu S, Ciohat I, Gidea R, Nemescu D, et al: Influence of weight of pregnant women on first trimester biochemical markers values. Rev Chim 68: 2836-2838, 2017.

42. Navolan D, Vladareanu S, Ciohat I, Carabineanu A, Craina M, Nemescu D, Birsasteanu B, Onofriescu A, Boia M, Tepetzikiotis E, et al: Distribution of biochemical and ultrasound markers values in the first trimester screening program in timisoara. Rev Chim 68: 1636-1639, 2017

43. Navolan D, Nicolov M, Vladareanu S, Ciohat I, Craina M, Tomovic M, Nemescu D, Onofriescu A, Craciunescu M and Birsasteanu F: Is there a need for own median calculation in the second trimester biochemical markers screening? Rev Chim 68: 1070-1072, 2017.

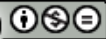

This work is licensed under a Creative Commons Attribution-NonCommercial-NoDerivatives 4.0 International (CC BY-NC-ND 4.0) License. 